\title{
Comentário VI
}

\author{
Gavin Adams \\ Artista plástico
}

Um artista e a coleção

Neste texto tento apresentar algumas breves reflexões acerca das conseqüências das aplicações digitais na organização e disponibilização de acervos a partir do ponto de vista parcial e específico do que Ricardo Mendes chamou de um "usuário especializado", no caso deste autor, um artista plástico. Espero que esta pequena contribuição enriqueça a ampla e rica discussão proposta. Procurarei apresentar breves reflexões sobre dois elementos desse debate mais amplo, que também envolve muitos outros atores e cenários. Tais elementos são o confronto com catálogos digitais no processo de pesquisa artística e a participação do artista na reflexão sobre a organização e criação de ferramentas de pesquisa para coleções.

1. Apesar de ser uma questão premente e interessante, pouco parece ter sido escrito a respeito da pesquisa artística. Uma exceção é o livro de PAYNE, 2000. Essa publicação, em que a questão da pesquisa artística é discutida em relação ao ensino de arte nas escolas britânicas contemporâneas, poderá acrescentar ao debate no Brasil.

A pesquisa artística

A pesquisa é parte do trabalho do artista. $\bigcirc$ uso do singular "artista" abrange a prática artística em sua enorme variedade. Não cabe aqui tentar uma definição do que constitui um artista, ou mesmo o que exatamente constitui a pesquisa artística, mas apenas sublinhar que a pesquisa é parte da prática artística. Nas palavras da curadora Sandy Naime':

Os artistas claramente desenvolvem uma forma de pesquisa em seu trabalho. Esta pesquisa pode se estender de investigações programáticas sobre a cor, forma ou materiais até a relação entre arte, filosofia e linguagem. Tal pesquisa era um dos eixos do projeto renascentista. Não obstante, a partir do Romantismo, com a separação geral entre as artes e as ciências e a promoção do culto do espírito criativo inspirado, a pesquisa artística tomou forma diferente (e tem uma finalidade diferente) da pesquisa científica. Talvez o que seja importante hoje é entender o porquê que os artistas trabalham nas diversas maneiras com que o fazem, e que questões estão a tentar responder através de seu trabalho (in PAYNE, 2000, p. 11. Tradução do autor). 
Tento com essa citação situar o artista como um pesquisador natural, que, potencialmente pelo menos, tem um leque de interesses que o levará às instituições e museus para a realização de sua pesquisa. Atualmente, os temas que ele ou ela procuram poderão alcançar além do esperado (história da arte, pinturas, fotografias ou vestuário e arquitetura), tocando áreas mais distantes como linguagens arquivísticas, sistemas organizacionais e operacionais, procedimentos críticos e curatoriais. Potencialmente, portanto, o artista é tanto usuário como parceiro na organização de coleções.

Para contribuir na discussão acerca das aplicações digitais na organização e disponibilização de acervos, tomarei como ponto de partida um tipo "analógico" de organização de documentos que considero ideal sob a perpectiva da pesquisa artística: a biblioteca de prateleiras abertas. A seguir, considerarei os sistemas digitais em relação a esse tipo de biblioteca, sempre do ponto de vista parcial e incompleto de minha experiência pessoal.

A organização ideal para a pesquisa artística

O lugar ideal de pesquisa como artista é, para mim, a biblioteca de prateleira aberta. Esse modelo atende tanto ao vouyerismo mais preguiçoso quanto à busca mais pontual e rigorosa, pois permite a manipulação direta de todos os volumes e verificação de seu conteúdo. A disposição espacial dos livros em corredores e alas convida a uma busca instigante, onde certa imprevisibilidade está em jogo. Como em uma espécie de grande labirinto semântico, estamos convidados a formular hipóteses sobre a organização dos livros e sobre a localização de um volume ou tipo de publicação em particular. Se a pergunta da instituição organizadora é aquela normalmente feita pelo bibliotecário zeloso, "o que você procura?", a resposta do artista poderá ser "eu não sei, mas saberei quando encontrar." O que quero sublinhar é que certa prática mais instintiva de pesquisa pode ser encenada pelo artista-usuário na biblioteca de prateleira aberta, onde ele pode encontrar o que não sabia procurar.

Seria possível, creio, defender o pesquisador-artista como puro flâneur de biblioteca, mas isso está fora do escopo deste comentário. O que nos interessa é a biblioteca como modelo de interface com o usuário. Dentro de minha experiência, existe ao menos uma especificidade na pesquisa do artista que é contemplada somente pela biblioteca de prateleira aberta, um tipo de informação raramente relacionada na ficha ou ao alcance do bibliotecário: a qualidade das ilustrações. Essa é a experiência insubstituível que esse tipo de biblioteca oferece, e que só o folhear de títulos pode dar conta. Falamos das ilustrações em termos de sua existência ou não dentro de um título, de seu número, de sua qualidade gráfica, de suas cores, de suas dimensões, de seu viés (documental, ilustrativo ou técnico), etc.

que temos então parece ser uma dificuldade de sistemas de organização e disponibilização de acervos em lidar com a informação visual, 
exceto se traduzida em termos textuais. Quando a descrição numérica ou textual é possível (por exemplo, o número de ilustrações e processo de impressão em cores ou preto-e-branco), a ficha (ou o bibliotecário) pode dar conta de maneira eficiente. Mas para além disso, só a manipulação direta dos livros pode responder às necessidades de pelo menos uma parte da pesquisa artística, já que muitas vezes a prática do artista é inteira ou principalmente visual.

Esse sistema de prateleiras abertas não é facilmente aplicável a outros tipos de documento visual, como pinturas, mapas, fotografias ou gravuras. $\bigcirc$ que permite a ordenação literalmente ao alcance da mão é justamente a padronização do formato livro, ao qual toda a informação é reduzida. Fotos avulsas, quadros, esculturas e objetos não se adaptam bem à arquitetura da biblioteca aberta. Aqui os sistemas digitais vêm em socorro do artista.

Sistemas digitais e a pesquisa artística

Os sistemas digitais com que tive contato por um lado trazem o que há de bom da biblioteca de prateleira aberta, mas por outro, carregam incontornáveis limitações. Suas maiores vantagens se apresentam menos nos casos de livros, e mais no caso de documentos visuais, tais como fotografias ou gravuras. No primeiro caso, os sistemas digitais têm potencialmente grande facilidade em trazer algum tipo de informação visual adicional, ainda que seu uso real seja limitado. As livrarias virtuais como a Amazon trazem uma imagem reduzida (thumbnail), que oferece, entre outros, pistas sobre a qualidade gráfica das páginas internas. Seria demais, não obstante, atribuir qualquer grau de confiabilidade científica a esse método. $\bigcirc$ que esse exemplo pretende sublinhar é que a ausência de um tipo de informação visual só acessível pelo contato direto com o volume pode ser mitigada pela sua adição na sua respectiva ficha, um procedimento antes só realizável no sistema de microfilmagem ou no catálogo ilustrado, que não é a regra para livros.

No caso de outros documentos, como fotografias, pinturas ou gravuras, as vantagens dos sistemas digitais são ainda mais evidentes. Em adição às informações que constariam em uma ficha analógica, pode-se acrescentar informações visuais, na maioria dos casos a totalidade da informação pictórica (e não necessariamente visual, que poderia incluir o verso de imagens, por exemplo).

A tensão que se desenha aqui, portanto, parece ser o caráter textual das descrições que compõem o catálogo. Em outras palavras, mesmo se a totalidade de uma coleção está disponível para o "folhear" visual, a pesquisa ou busca dentro desse universo potencialmente enorme é feita por meio da palavra.

Como no país de Borges, em que o empuxo indicial da cartografia local acabou por levar à feitura de um mapa nas idênticas proporções do território, a ficha ideal seria aquela em que o objeto está transferido para o registro em 
sua totalidade mais absoluta. Portanto a descrição parcial do objeto é realidade inevitável, a despeito das promessas da informação total pela informática. É essa parcialidade que excita a eterna pergunta que angustia o pesquisador: esgotaram-se as imagens ou esgotou-se o descritor? A tensão e a angústia decorrentes da passagem entre os códigos textuais e visuais parecem ter estimulado a pesquisa na procura de buscadores puramente visuais. Quando for possível ensinar o computador a distinguir elementos como figura e plano de fundo, um enorme salto terá sido dado.

Até aqui trabalhamos com a noção do artista como usuário especializado, e, na parcialidade do meu ponto de vista, identificamos uma tendência visual na condução de pesquisa em acervos e coleções. Apesar de específico, o artista como usuário não apresenta enormes diferenças em relação a outros tipos de usuários, que também operam confortavelmente em termos visuais. Vimos como a agilidade e a rapidez na manipulação das imagens digitais aproximam a pesquisa em um catálogo digitalizado de uma visita à biblioteca de prateleira aberta, tida por mim como a organização ideal para a pesquisa artística.

Mas onde a especificidade da pesquisa artística pouco distingue o artista de um usuário especializado, os resultados da pesquisa ou a apresentação da reflexão gerada por ela podem marcar diferenças mais importantes, ao fazer do artista um parceiro potencial do arquiteto de software e da pesquisa acadêmica, desempenhando enfim um papel mais ativo na reflexão sobre adoção de sistemas digitais no contexto de acervos.

artista na construção crítica de sistemas digitais de organização

Pelo menos parte dos usuários artistas estará atenta à forma pela qual uma coleção está organizada e apresentada. De fato, artistas como Kandinski ou Joseph Beuys

viam a si mesmos testando os limites da experiência. A arte era seu veículo particular. Certamente eles testavam as maneiras em que a experiência humana poderia ser expressada e comunicada. [...] A arte, como a escrita criativa, adicionou muito à reflexão sobre as maneiras em que a linguagem predetermina até os próprios meios com que somos capazes de debater a arte e seu significado (Nairne in PAYNE, 2000, p. 11. Tradução do autor).

Dessa forma, a contribuição do artista pode transcender o uso instrumental de acesso a conteúdo e fazer dele um ator mais ativo na formulação de estratégias e arquitetura organizacional de uma coleção ou acervo.

De um lado, o artista plástico tem perante si um vasto território documental e uma produção científica que merece ser apropriada e, do outro, o museu que atualmente não pode prescindir da criatividade do artista para a realização plástica de problemáticas desenvolvidas nos moldes textuais da academia. Há um campo comum às práticas artística e museológica: a formulação 
de hipóteses de agrupamento, de parentescos e vínculos entre as imagens e a análise dos resultados obtidos. Se a validade e relevância dos resultados separam um do outro, os une o exercício de experimentar com diferentes pesos e medidas, de eleger um princípio organizador e com ele articular discursos sobre uma coleção. Apesar da parceria artista-museu não ser nova ${ }^{2}$ no mundo, freqüentemente tomando a forma de residências, no Brasil a prática parece ser limitada. O formato residência de artistas em museus poderia fomentar tal parceria.

Das ricas e interessantes possibilidades derivadas dessa parceria, será necessário estreitar o leque e considerar apenas aspectos ligados à adoção de sistemas digitais de organização e disponibilização de acervos e coleções, e dentre eles, escolher um elemento principal, que é o uso de tecnologia digital na organização e apresentação de material histórico visual.

Os museus parecem enfrentar hoje dilemas relativos ao desempenho da exposição de seu acervo perante os seus objetivos educacionais, culturais e de fruição estética. Um uso por vezes quase abusivo de recursos de multimídia, imagens eletrônicas e cenarizações do gênero parque temático forja um passado estilizado com o qual o espectador se relaciona acriticamente. $\bigcirc$ artista é com freqüência chamado ao museu para dar forma a essas leituras. Ricardo Mendes, em seu texto, referiu-se com aguda lucidez ao hiperobjeto que por vezes é fabricado a partir de documentos visuais, e essa me parece ser uma área em que um intenso debate deve ocorrer, inclusive com os artistas, para que sejam evitadas as armadilhas apontadas por Mendes (e muitas outras) que o uso de meios digitais pode acarretar. Parece-me ser esse o caso com as reconstituições digitais de ambientes do passado. $\bigcirc$ hiperobjeto e o "gesto publicitário" podem ser respostas discutíveis dos museus às pressões desses dilemas.

Muito se fala e se discute a respeito da perda da autoridade indicial da imagem fotográfica nos dias de hoje: a noção do original e da cópia perdeu sua força explicativa no mundo digital, onde as cópias são perfeitas - clones portanto sem hierarquia de precedência ou perfeição. Mas se essa explosão da noção de matriz e cópia for incompleta, ela pode provocar nova aderência do significante ao significado, para usar o jargão em voga nas escolas de arte 10 anos atrás. Isso se dá mais claramente nas reconstituições históricas por meio de tecnologias digitais. Um perigo inerente ao uso de tecnologias digitais, no meu entender, é a formação da "janela para o passado", na qual a modernidade e a autoridade do digital realizam uma espécie de retrocesso em direção ao indicial, em que a imagem digitalizada de origem fotográfica carrega a vocação do registro supostamente transparente da realidade.

Nesse sentido, a instalação Animatoscópio (parte da exposição Olho cíclico, realizada no Museu Paulista) procurou, entre erros e acertos, desencorajar a formação da "janela para o passado". A velocidade com que as imagens se sucedem na tela e o padrão de repetição, que provocam efeitos de cinema de animação, fazem as imagens descolar de seus referidos, assim fica difícil ao usuário crer que atinge, vê ou presencia o indivíduo cuja imagem está projetada na tela. $\bigcirc$ que vem para o primeiro plano são os padrões de pose, convenção de composição, incidência de móveis, etc., que se tornam visíveis no papel de
2. Para citar um único exemplo, o curador do British Museum, James Putnam, convidou em 1995 artistas como Francesco Clemente, Andy Goldsworthy, Mimmo Paladino e Marc Quinn a lançarem seus olhares sobre a coleção de arte egípcia sob a guarda do museu. Expostas no es paço das coleções, essas experiências puderam oferecer ao público visões e organizações de coleções e peças diversas daquelas consagradas pela curadoria histórica e arqueológica. James Putnam esteve em São Paulo para participar do ciclo de debates promovido pelo Museu Paulista na ocasião da abertura da exposição Olbo cíclico em janeiro de 2004. 
bloqueadores da realização fetichista do desejo indicial. Em outras palavras, o que nos impede de ver os indivíduos como eles eram é precisamente sua representação na forma do próprio registro fotográfico. Da mesma forma, a seqüência animada Ambientes, ao se propor a "reconstituir" o espaço do estúdio do fotógrafo Militão de Azevedo, foi programada para falhar visível e miseravelmente nessa reconstituição. Nela, além de não obtermos uma visão de como era o estúdio (no máximo recortes dos panos de fundo e nesgas de chão), as diferenças de pontos de vista tornam o espaço instável e pouco claro. A mensagem pretendida, do lado artístico pelo menos, foi a de que não há reconstituição fiel nem imersão possível no passado: o que temos são suas representações. O passado permanece fora de nosso alcance, exceto como fantasmagoria. 